\title{
Pre-Androgen Ablation Prostate Cancer Patients Who Bleed Do Well with 5 Alpha Reductase Inhibitors
}

\author{
Vitalis Obisike Ofuru1 ${ }^{*}$, Christopher Chinedu Obiorah² \\ ${ }^{1}$ Urology Division, Department of Surgery, University of Port Harcourt Teaching Hospital, Port Harcourt, Nigeria \\ ${ }^{2}$ Department of Anatomical Pathology, University of Port Harcourt Teaching Hospital, Port Harcourt, Nigeria \\ Email: *vitalisoofuru@gmal.com
}

How to cite this paper: Ofuru, V.O. and Obiorah, C.C. (2018) Pre-Androgen Ablation Prostate Cancer Patients Who Bleed Do Well with 5 Alpha Reductase Inhibitors. Open Journal of Urology, 8, 184-192. https://doi.org/10.4236/oju.2018.86020

Received: May 2, 2018

Accepted: June 22, 2018

Published: June 25, 2018

Copyright $\odot 2018$ by authors and Scientific Research Publishing Inc. This work is licensed under the Creative Commons Attribution International License (CC BY 4.0).

http://creativecommons.org/licenses/by/4.0/

\begin{abstract}
Background: Patients with gross haematuria are sometimes found to have prostate cancer after clinical evaluation. The treatment of such haematuria could be very challenging. Use of a 5 alpha reductase inhibitor like dutasteride has been found helpful in bleeding prostate cancer patients if they have not undergone hormonal manipulation before they developed haematuria. Patients and Method: 26 patients with gross haematuria of prostatic origin who had histologic confirmation of adenocarcinoma of the prostate but who have not had chemical or surgical castration were randomized to receive daily dutasteride in addition to vigorous saline irrigation and antibiotics on one arm and vigorous saline irrigation and antibiotics only as control on the other arm. The time taken before haematuria resolved and the amount of irrigation fluid used were noted. Statistical analysis was done using SPSS. Student's t-test and Kaplan Meier survival analysis were used to test various variables at 0.5 significant levels. Results: Of the 26 patients $12(46.2 \%)$ received $0.5 \mathrm{mg}$ oral dutasteride in addition to saline irrigation while $14(53.8 \%)$ received saline irrigation only. Haematuria stopped in all of $12(100 \%)$ patients on dutasteride arm but on $12(85.7 \%)$ of the 14 patients on the control arm. It took significantly shorter time and lesser volume of irrigation fluid before haematuria resolved in those treated with dutasteride than in those on the control arm. Conclusion: Dutasteride is effective in the control of acute haematuria in pre-androgen ablation prostate cancer patients.
\end{abstract}

\section{Keywords}

Prostate Cancer, Bleeding, 5-Alpha Reductase Inhibitors 


\section{Introduction}

Malignant prostates sometimes bleed. About $8 \%$ of acute gross haematuria are caused by cancer of the prostate [1]. Haematuria of cancer of prostate origin can occur from different sources. It can result from the cancer itself or as a side effect of previous treatments such as haematuria resulting from acute or chronic toxicity of radiotherapy, and haematuria resulting from a site of stone formation on a suture line in patients who have had radical prostatectomy [2]. Haematuria commonly results from prostate cancer patients who had external beam radiotherapy, however, such haematuria is often mild and self-limiting [3]. Prostate cancer patients who have had palliative transurethral resection of the prostate (TURP) also tend to have higher risk of late haematuria, especially if they also receive radiotherapy [4].

There is a subset of prostate cancer patients with haematuria seen in our centre. They have not been diagnosed with prostate cancer previously but present for the first time with haematuria. Majority of these patients were rural dwellers who either did not have access to specialist care or could not afford one. They presented for the first time with advanced disease, with an enlarged prostate and high serum prostate specific antigen (PSA). Haematuria in these patients could come from the prostate cancer itself in which case it arises from the peripheral zone, away from the urethra. For such tumor to have caused haematuria, they must have encroached on the transition zone. However, the bleeding may also come from a coexisting benign prostatic hyperplasia [5]. When haematuria results from prostate cancer directly, it is said to be of dismal prognosis [2]. The aim of management in such patients would be first, to control the bleeding and while doing this effort is made to make diagnosis and institute definitive treatment.

At centres where the facilities are readily available, such patients in whom curative surgical treatments are not intended have been managed with parliative TURP [6]. Recalcitrant cases of prostatic bleeding benefit from embolization using femoral accesses or selective prostatic arterial embolization [7]. In a resource poor setting such as ours, patients who present in this manner could pose real management challenge. Successful use of an oral drug to control this life threatening condition while plans are made for definitive care could therefore be of immense benefit.

Dutasteride is a competitive inhibitor of type 1 and $25 \alpha$ reductase isoenzymes [8]. The drug binds to $5 \alpha$ reductase enzymes forming stable complexes with slow rate of dissociation. This action prevents $5 \alpha$ reductase enzymes from binding to testosterone [9].

We are not aware of any evidence in the literature of the use of dutasteride or its analogue finasteride in the management of haematuria from prostate cancer origin, although these drugs have variously been used in haematuria of Benign Prostatic Hyperplasia (BPH) origin [10] [11]. In fact, Dahala et al. [12] cautioned against the use of finasteride in prostate cancer. 
In this study, we prospectively randomized cases of prostatic bleeding who presented to our centre, but who had not had androgen manipulation or any form of prostate cancer treatment into two arms of treatment, a combined dutasteride and saline irrigation arm on one hand and saline irrigation arm only as control. Time to resolution of haematuria and volume of irrigation fluid used on both sides were used as outcome measures. The influence of dutasteride, a dual 5 alpha reductase inhibitor on acute cases of prostate cancer bleeding was determined accordingly.

\section{Patients and Method}

Consecutive patients with gross haematuria suspected to be of prostatic origin, who presented to the urology division of University of Port Harcourt Teaching Hospital between January 2012 and June, 2014 were recruited. Serum PSA, digital rectal examination (DRE), prostate scan and cystoscopy were carried out. A total of 64 patients had features suggestive of prostate cancer. 19 of them were found to have hard or nodular prostates and 45 of them had serum PSA $\geq 10$ $\mathrm{ng} / \mathrm{ml}$. All had prostate biopsy and histologic evaluation. Of this number, 26 were found to have adenocarcinoma of the prostate.

The 26 patients were randomized into two treatment groups by simple randomization with allocation concealment; each patients was made to choose one of two options, each option being concealed in a wrap. One group received vigorous bladder irrigation with normal saline using size 22 or 24 Foley 3-way urethral catheter and broad spectrum antibiotics. The other group received $0.5 \mathrm{mg}$ oral dutasteride in addition to bladder irrigation and antibiotics. The time taken before haematuria resolved and the volume of irrigation fluid used were noted as outcome measures. Two sample student's t-test was used to determine whether the volume of irrigation fluid used for the two groups were different. Kaplan Meier Survival analysis was used to examine the distribution of time it took before haematuria resolved for the two groups. Pearson correlation analysis was used to determine relationship between prostate size and duration of haematuria. Statistical significant was determined at $p$ value of 0.5

\section{Results}

The mean age of the patients was $71.4 \pm 9.0$ years. The serum PSA ranged from $3.0 \mathrm{ng} / \mathrm{ml}$ to $134.0 \mathrm{ng} / \mathrm{ml}$ with a mean PSA of $47.9 \pm 42.1 \mathrm{ng} / \mathrm{ml}$ and modal PSA of $120.0 \mathrm{ng} / \mathrm{ml}$. Prostate size ranged from $56.0 \mathrm{~g}$ to $296.3 \mathrm{~g}$ with mean prostate size of $131.5 \pm 11.4 \mathrm{~g}$ and median prostate size of $119.5 \mathrm{~g}$ (Table 1 ). Of the 26

Table 1. Demographic features.

\begin{tabular}{cccc}
\hline & Age (yrs) & Serum PSA ng/ml & Prostate Size (g) \\
\hline Range & $49-88$ & $3-134$ & $56-296.3$ \\
Mean & $71.4+9.0$ & $47.9+42.1$ & $131.5+11.4$ \\
\hline
\end{tabular}

PSA = Prostate Specific Antigen. 
patients histologically confirmed to have prostate cancer, $12(46.2 \%)$ received daily $0.5 \mathrm{mg}$ oral dutasteride in addition to normal saline irrigation while 14 (53.8\%) received normal saline irrigation only. Haematuria stopped in all of 12 (100\%) patients on dutasteride arm but on $12(85.7 \%)$ of the 14 patients on the normal saline control arm. In $2(14.3 \%)$ patients on the control arm haematuria did not resolve after 30 days, so they were offered subcapsular orchidectomy. Haematuria resolved within $24 \mathrm{hrs}$ of surgery. The patients on the dutasteride arm required between 3 litres and 20 litres with a mean volume of $8.3 \pm 4.6$ litres of irrigation fluid before haematuria resolved while those on the control arm required between 4 litres and 48litres with a mean volume of $17.4 \pm 9.7$ litres before haematuria resolved (Table 2). Two sample student's t-test showed a statistically significant difference between the mean volume of irrigation fluid used for the two groups in favour of those who used dutasteride $(t=-4.155, p=$ 0.000, (Table 3).

Haematuria lasted between 1 day to 8 days with a mean time of $4.7 \pm 1.9$ days in those treated with dutasteride whereas on those on the control arm it lasted between 3 days and 10 days with a mean time of $6.9 \pm 2.3$ days (Table 2). Kaplan Meier Survival analysis showed that there was a significant chance of survival (earlier resolution of haematuria) in favour of those who received dutasteride (Figure 1). Student's t-test showed no significant difference between the mean prostate sizes of patients that received dutasteride in addition and the mean prostate sizes of those on the control arm $(t=0.275, p=0.784)$ (Table 4). Pearson correlation analysis of prostate size and duration of haematuria showed positive correlation which was statistically significant $(\mathrm{R}=0.290, p=0.012)$ (Table $5)$.

\section{Discussion}

The aim of management in haematuria is to control the bleeding, confirm diagnosis

Table 2. The minimum, maximum and mean duration of haematuria (in days) and the minimum, maximum and mean volume of irrigation fluid (in litres) used for each treatment type.

\begin{tabular}{ccccccccc}
\hline Diagnosis & TT & N & Min DUR & Max DUR & MD + SD & Min Vol & Max Vol & MV + SD \\
\hline \multirow{2}{*}{$\mathrm{CaP}$} & N/S +DUT & 12 & 1 & 8 & $4.7 \pm 1.9$ & 3 & 20 & $8.3 \pm 4.6$ \\
& N/S only & 14 & 3 & 10 & $6.9 \pm 2.3$ & 4 & 48 & $17.4 \pm 9.7$ \\
\hline
\end{tabular}

$\mathrm{BPH}=$ Benign prostatic hyperplasia, $\mathrm{CaP}=$ Prostate cancer, $\mathrm{TT}=$ Treatment type, $\mathrm{N} / \mathrm{S}=$ Normal saline, DUT $=$ Dutasteride, $\mathrm{N}=$ No of patients, Min $=$ Minimum, Max $=$ Maximum, $\mathrm{DUR}=$ Duration, $\mathrm{MD}=$ Mean Duration, $\mathrm{MV}=$ Mean Volume, $\mathrm{SD}=$ Standard deviation

Table 3. Comparison of the mean volume of irrigation fluid used before haematuria resolved for each treatment type, student's t-test and $p$ value.

\begin{tabular}{|c|c|c|c|c|}
\hline \multirow{2}{*}{ Diagnosis } & N/S and DUT & N/S only & \multirow{2}{*}{ t-test } & \multirow{2}{*}{$P$-value } \\
\hline & Mean \pm SD & Mean \pm SD & & \\
\hline $\mathrm{CaP}$ & $8.3 \pm 4.6$ & $17.4 \pm 9.7$ & -4.155 & 0.000 \\
\hline
\end{tabular}

$\mathrm{N} / \mathrm{S}=$ Normal saline, $\mathrm{DUT}=$ Dutasteride, $\mathrm{BPH}=$ Benign prostatic hyperplasia, $\mathrm{CaP}=$ Prostate cancer . 
Table 4. Comparison of the mean prostate size by treatment (student's t-test analysis).

\begin{tabular}{|c|c|c|c|c|c|}
\hline \multicolumn{2}{|c|}{ Treatment } & \multirow{2}{*}{$\begin{array}{l}\mathrm{N} \\
12\end{array}$} & \multirow{2}{*}{$\begin{array}{l}\text { Mean } \\
134.8\end{array}$} & \multirow{2}{*}{$\begin{array}{c}\text { Std. Deviation } \\
47.6\end{array}$} & \multirow{2}{*}{$\begin{array}{c}\text { Std. Error Mean } \\
7.9\end{array}$} \\
\hline \multirow{2}{*}{ Prostate Size } & $\begin{array}{c}\text { Normal Saline and } \\
\text { Dutasteride }\end{array}$ & & & & \\
\hline & $\begin{array}{l}\text { Normal Saline } \\
\text { Irrigation only }\end{array}$ & 14 & 131.5 & 55.6 & 8.9 \\
\hline
\end{tabular}

$T=0.275 ; P$-value 0.784 .

Table 5. Correlation analysis of prostate size and duration of haematuria.

\begin{tabular}{lccc}
\hline & & Duration of Haematuria & Prostate Size \\
\hline & Pearson Correlation & 1 & $0.290^{*}$ \\
Duration of & Sig. (2-tailed) & & 0.012 \\
Haematuria & $\mathrm{N}$ & 26 & 75 \\
\hline
\end{tabular}

$R=0.290 ; P$-value 0.012 .

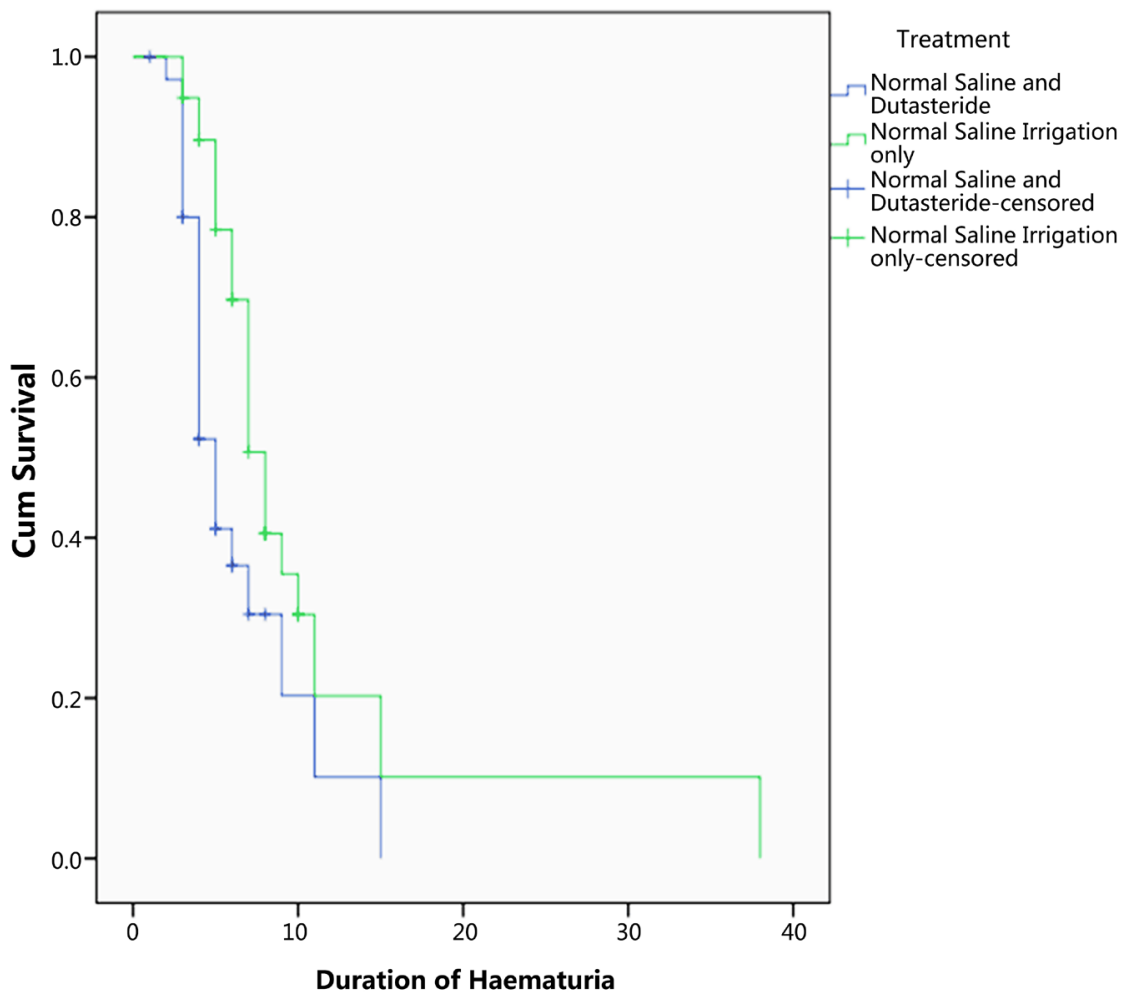

Figure 1. Kaplan Meier survival analysis showing higher tendency to survive (earlier resolution of haematuria) in those who had dutasteride in addition.

and then offer definitive treatment according to the cause of haemauria. However, because this study aimed to study the efficacy of oral dutasteride in acute bleeding in prostate cancer cases, the drug was given to all the selected cases of prostatic haematuria at presentation even when the diagnosis was not certain. Normal saline irrigation which is traditionally the first approach employed in the control of acute haematuria was also commenced at the same time, alongside 
efforts to make diagnosis.

It is to be noted that bladder irrigation with normal saline is not strictly a form of treatment. Irrigation primarily serves the purpose of removing blood clots to prevent infection, although it has been argued that it decreases bleeding by washing away urokinase, a serine protease that prevents blood clot formation [13]. In occasions as in this study, antibiotics are added in anticipation of or to treat infection. Because both normal saline irrigation and antibiotics were used on the both arms of treatment, it will be assumed that their effect on the outcome had been neutralized.

Significantly lesser number of days and lesser volume of irrigation fluid were used in patients who received dutasteride as against those on the control arm in this study. This could suggest that the drug had influence on whatever mechanism that caused bleeding in prostate cancer.

It is known that 5 alpha reductase inhibitors prevent the conversion of testosterone to dihydrotestosterone (DHT). It is also known that DHT stimulates the elaboration of vascular endothelial growth factor (VEGF) in the prostate tissue, and that VEGF is the androgen sensitive growth factor that controls angiogenesis [14]. Finasteride a type 2, 5-alpha reductase inhibitor has been found to reduce intraprostatic levels of DHT by as much as $85 \%$ within one week of its usage [15]. This mechanism of action has been explored in its preoperative use to reduce bleeding during transurethral prostatectomy in patients with $\mathrm{BPH}$ [16]. Similarly, dutasteride, a type 1 and 2 analogue has been used for this purpose [17].

Long term androgen deprivation has been demonstrated to significantly decrease risk of haematuria in locally advanced prostate cancer patients, even when they were primarily treated with high dose external beam radiotherapy [18]. However in this study, bleeding resolved in prostate cancer patients who had not had any form of treatment in the past at an average time of only 5 days when dutasteride was used. This might be due to the fact that dutasteride reduces microvascular density in prostate cancer directly [5]. It might also be due to the fact that 5 alpha reductase enzyme inhibitors reduce the inflammatory effect of vascular endothelial growth factor, vegf in prostate tissue [19], hence reducing bleeding. The central point here is that androgen is crucial to bleeding from the prostate irrespective of the underlying pathology. Accordingly reduction or removal of androgen is a key factor in control of bleeding from the prostate.

Other forms of androgen deprivation, for example use of anti androgens and castration also reduce prostatic vascularity at least as well as 5ARIs [20]. However, these methods have higher morbidity than 5ARIs making them less attractive treatments for haematuria. They however find utility if other indications for androgen deprivation are present in addition to haematuria [20]. In this study, we observed that two patients on the control arm continued to bleed for more than 30 days of commencement of treatment. These two patients were offered bilateral subcapsular orchidectomy. Haematuria resolved in both patients within 24 hours of surgery. The experience in these two patients corroborates the fact that 
presence of androgens play central role in the pathogenesis of prostate cancer bleeding [19] [21]. Removal of androgen is equally important for the treatment of haematuria as demonstrated here; serum level of testosterone and DHT drop by greater than $90 \%$ after orchidectomy [22].

Perhaps the important facts in making decision on the form of androgen manipulation during prostate cancer bleeding are the clinical stage of the disease, the aim of treatment and the available resources. Oral dutasteride is readily available and relatively affordable, and can be used palliatively to control bleeding in cases of locally advanced prostate cancer haematuria where modern and appropriate facilities are available and definitive care can be given after haematuria is controlled. But in a resource poor setting where indigent patients with locally advanced prostate cancer present with haematuria, subcapsular orchidectomy may serve the dual purpose of quick control of bleeding as well as offer primary treatment option for the prostate cancer. Otherwise, oral dutasteride can be used for the control of haematuria while other options for definitive care are considered.

The average prostate weight of $131.5 \mathrm{~g}$ in this study is similar to average weight of $127 \mathrm{~g}$ observed in another study carried out in the Northern part of Nigeria among patients with bleeding prostates [23]. This fact, and the positive correlation between prostate size and the duration of haematuria in this study ( $\mathrm{R}$ $=0.290, P=0.012)$ (Table 5) suggest that patients with markedly enlarged prostates are prone to bleed. Such patients should be closely monitored and may benefit from prophylactic 5 alpha reductase inhibitors therapy.

The clinical condition whereby patients who had not been diagnosed with prostate cancer present for the first time with haematuria is relatively rare; accordingly, the sample size was small which may be a limitation in this study. A long term multicentre study may be necessary therefore. Again, few clinically very ill patients were by choice put in the intervention arm of the study to improve their chances of survival; selection bias is a limitation therefore.

\section{Conclusion}

We conclude that dutasteride is very effective in prostatic bleeding and can be used in cases of prostate cancer patients who have not had androgen manipulation before they developed haematuria. We also conclude that surgical castration should be employed in advanced prostate cancer cases with bleeding; in patients in whom it is indicated, surgical castration serves a dual purpose of primary cancer treatment and haematuria control.

\section{References}

[1] Mbonu, O.O., Amene, P.C. and Nwofor, A.M. (1991) Gross Haematuria in a Negro Population: An Analysis of 100 Adult Patients. International Urology and Nephrology, 23, 261-263. https://doi.org/10.1007/BF02550422

[2] Gofrit, O.N., Katz, R., Pizov, G., Zarn, K.C., Duvdevani, M., Landau, E.H., et al. (2013) Gross Haematuria in Patients with Prostatic Cancer: Etiology and Manage- 
ment. ISRN Surgery, 2013, Article ID: 685327. https://doi.org/10.1155/2013/685327

[3] Del Regato, J.A., Trailins, A.H. and Pittman, D.D. (1993) Twenty Years Follow up of Patients with Inoperable Cancer of Prostate (Stage C) Treated by Radiotherapy: Report of a National Co-Operative Study. International Journal of Radiation Oncology • Biology • Physics, 26, 197-201. https://doi.org/10.1016/0360-3016(93)90197-4

[4] Devisetty, K., Zorm, K.C., Katz, M.H., Jani, A.B. and Liauw, S.L. (2010) External Beam Radiation Therapy after Transurethral Resection of the Prostate: A Report on Acute and Late Genitourinary Toxicity. International Journal of Radiation Oncology • Biology • Physics, 77, 1060-1065. https://doi.org/10.1016/j.ijrobp.2009.06.078

[5] Andriole, G.L., Humphrey, P., Ray, P., et al. (2004) Effect of the Dual 5 Alpha Reductase Inhibitor Dutasteride on Markers of Tumor Regression in Prostate Cancer. Journal of Urology, 72, 915-919. https://doi.org/10.1097/01.ju.0000136430.37245.b9

[6] Crain, D.S., Amling, C.L. and Kane, C.J. (2004) Palliative Transurethral Prostate Resection for Bladder Outlet Obstruction in Patients with Locally Advanced Prostate Cancer. Journal of Urology, 171, 668-671.

https://doi.org/10.1097/01.ju.0000104845.24632.92

[7] Rodriquez-Patron, R.R., Sanz-Mayoyo, E., Gomer, G.I., Blazquez, S.J., Sandez, C.J., Briones, M.G., et al. (2003) Hypogastric Artery Embolization as a Palliative Treatment for Bleeding Secondary to Intractable Bladder or Prostate Diseases. Archivos Españoles de Urología, 56, 111-118.

[8] Djavan, B. and Mirone, V. (2006) The Benefits of Dual Inhibitors of $5 \alpha$ Reductase. European Urology Supplements, 5, 1013-1017.

[9] Branson, H.N., Hermann, D., Bachelor, K.W., Lee, F.W., James, M.K. and Frye, S.V. (1997) Unique Preclinical Characteristics of GG745, a Potent Dual Inhibitor of 5 Alpha Reductase. Journal of Pharmacology and Experimental Therapeutics, 282, 1496-1502.

[10] Buccon-Gibod, L., Valton, M., Ibrahim, H. and Commenducci, A. (2007) Effect of Dutasteride on the Reduction of Intraoperative Bleeding Related to Transurethral Resection of the Prostate after Pre-Treatment with Dutasteride. BJU International, 99, 587-594.

[11] Moon, S.Y., Moon, W.C., Chio, H.R. and Gi, Y.J. (1998) Finansteride Inhibits Angiogenesis and Expression of Vascular Endothelial Growth Factor in Human Benign Prostatic Hyperplasia. Journal of Urology 1998, Supplement 159, 352-358.

[12] Dahala, D., Lianos, E., Karyotis, I. and Cranidis, A. (2001) Finansteride: A Long-Term Follow up in the Treatment of Recurrent Haematuria Associated with Benign Prostatic Hyperplasia. Urologia Internationalis, 67, 69-72. https://doi.org/10.1159/000050948

[13] Jankun, J. and Skrzypczak-Jankun, E. (1999) Molecular Basis of Specific Inhibition of Urokinase Plasminogen Activator by Amiloride. Cancer Biochemistry Biophysics, 17, 109-123.

[14] Haggstrom, S., T’rring, N., Miller, K., Jensen, E., Lund, L., Nielsen, J.E., et al. (2002) Effects of Finanseride on Vascular Endothelial Growth Factor. Scandinavian Journal of Urology and Nephrology, 36.

[15] Mc Connell, J.D., Wilson, J.D., George, F.W., Geller, J., Papper, F. and Stoner, E. (1992) Finansteride an Inhibitor of 5 Alpha-Reductase, Suppresses Prostatic Dihydrotstosterone in Men with Benign Prostatic Hyperplasia. The Journal of Clinical Endocrinology \& Metabolism, 74, 505-508.

[16] Hagerty, J.A., Ginsberg, P.C., Harmon, J.D. and Harkaway, R.C. (2000) Pretreat- 
ment with Finasteride Decreases Peri Operative Bleeding Associated with Transurethral Resection of the Prostate. Urology, 55, 684-689.

https://doi.org/10.1016/S0090-4295(00)00454-4

[17] Buccon-Gibod, L., Valton, M., Ibrahim, H. and Commenduci, A. (2007) Effect of Dutasteride on the Reduction of Intraoperative Bleeding Related to Transurethral Resection of the Prostate after Pre Treatment with Dutasteride. BJU International, 99, 587-594.

[18] Zapatero, A., Garcia-Vicente, F., Sevillano, D., Martin de Vindele, C., Ferrer, C., Torres, J.J., et al. (2008) Is Hormone Therapy a Protective Factor for Late Haematuria after High Dose Radiotherapy in Prostate Cancer? Urology, 72, 1130-1134. https://doi.org/10.1016/j.urology.2008.01.057

[19] Foley, S.J., Solomon, L.Z., Wedderburn, A.W., Kashif, K.M., Summerton, D., Basketter, V., et al. (2000) A Prospective Study of the Natural History of Haematuria Associated with Benign Protatic Hyperplasia and the Effect of Finasteride. Journal of Urology, 163, 496-498. https://doi.org/10.1016/S0022-5347(05)67910-4

[20] Kaya, C., Ozyurek, M. and Turkeri, L.N. (2005) Comparison of Microvessel Densities in Rat Prostate Tissues Treated with Finasteride, Bicalutamide, and Surgical Castration: A Preliminary Study. International Journal of Urology, 12, 194-198. https://doi.org/10.1111/j.1442-2042.2005.01005.x

[21] Sieber, P.R., Rommel, F.M., Huffnagle, H.W., Breslin, J.A., Agusta, V.E. and Harpster, L.E. (1998) The Treatment of Gross Haematuria Secondary to Prostate Bleeding with Finasteride. Journal of Urology, 159, 1232-1233. https://doi.org/10.1016/S0022-5347(01)63567-5

[22] Nelson, J.B. (2012) Hormone Therapy for Prostate Cancer. In: Wein, A.J., Ed., Campbell-Walsh Urology, 10th Edition, Saunders, 2926-2945.

https://doi.org/10.1016/B978-1-4160-6911-9.00109-2

[23] Ahmed, G.I., Aliyu, S. and Ali, N. (2014) Bleeding Prostate: A 10 Year Experience in the University of Maiduguri Teaching Hospital (UMTH), Nigeria. Sahel Medical Journal, 17, 79-82. https://doi.org/10.4103/1118-8561.140284 